\title{
Theoretical study of the substituent effect on corrosion inhibition performance of benzimidazole and its derivatives
}

\author{
S. Hadisaputra, ${ }^{1} *$ A.A. Purwoko, ${ }^{1}$ F. Wajdi, ${ }^{2}$ I. Sumarlan ${ }^{2}$ \\ and S. Hamdiani ${ }^{2}$ \\ ${ }^{1}$ Chemistry Education Division, Faculty of Science Education, University of Mataram, \\ Indonesia \\ ${ }^{2}$ Department of Chemistry, Faculty of Mathematic and Natural Science, University of \\ Mataram, Indonesia \\ *E-mail: rizal@unram.ac.id
}

\begin{abstract}
The substituent effects of electron-donating and -withdrawing on the efficiency of corrosion inhibition of benzimidazole and its derivatives have been studied by density functional theory DFT and Møller-Plesset perturbation theory MP2 calculations at aqueous medium. For this investigation, the corrosion inhibition efficiencies of the protonated and non-protonated spesies of benzimidazole and its derivatives were correlated with molecular electronic properties: high occupied molecular orbital (HOMO) and low unoccuppied molecular orbital (LUMO) energies, ionization potential, electron affinity, electronegativity and fraction number of electron transfer. The dipole moment and interaction energy represent the total surface coverage and the strength of the adsorption of inhibitors on the metal surface. Natural bond orbital NBO analysis in term of the second order interaction energies were used to study the contributions of the active sites of inhibitors toward corrosion inhibition performances. The ionization potential of the inhibitors has a strong influence on the efficiency of corrosion inhibitors. It was found that the MP2 method accurately predicted the ionization potential while the DFT failed to mimic the ionization potential of the experimental results. The linear correlation was shown between electronic properties and corrosion inhibition efficiency. Electron donating substituents increase the corrosion inhibition efficiency, whereas electron withdrawing substituents give the opposite effect. The $\mathrm{NH}_{2}$ substituent contributes highest, whereas $\mathrm{NO}_{2}$ provides the weakest contribution to the corrosion inhibition efficiency for both non-protonated and protonated species of inhibitors. The second order interaction energy indicated that heteroatom at imidazole position was the main center of electron donating and they received simultaneously significant amount of electron back donation from the metal.
\end{abstract}

Keywords: corrosion inhibition, benzimidazole, DFT, ab initio, substituent effect.

Received: August 25, 2019. Published: August 30, 2019

doi: $\underline{10.17675 / 2305-6894-2019-8-3-15}$ 


\section{Introduction}

The potential of benzimidazole and its derivatives as corrosion inhibitors has been widely reported, both in experimental [1-4] and theoretical studies [5-7]. Khaled studied the effect of substituents on the corrosion inhibition efficiency of benzimidazole, namely, 2aminobenzimidazole, 2-(2-pyridyl) benzimidazole, 2-aminomethylbenzimidazole, 2hydroxybenzimidazole using electrochemical impedance spectroscopy (EIS) on iron surfaces in $1 \mathrm{M} \mathrm{HCl}$ solutions. The study showed that the corrosion inhibition efficiency of benzimidazole increased with the presence of amine groups [8]. Aljourani et al. studied corrosion inhibition of 2-benzimidazole derivatives, namely, 2-mercaptobenzimidazole, 2methylbenzimidazole on mild steel derivatives in $1 \mathrm{M} \mathrm{HCl}$ solution. Addition of substituent in benzimidazole leads to a better corrosion inhibition efficiency than benzimidazole with no substituent [9]. In more detail the effect of the difference substituent types: 2-methylbenzimidazole (2- $\mathrm{CH}_{3}$-BI), 2-hydroxymethylbenzimidazole (2$\mathrm{CH}_{2} \mathrm{OH}-\mathrm{BI}$ ), 2-mminobenzimidazole (2- $\left.\mathrm{NH}_{2}-\mathrm{BI}\right)$, 2-mercaptobenzimidazole (2-SH-BI), 5(6)-nitrobenzimidazole (5(6)- $\left.\mathrm{NO}_{2}-\mathrm{BI}\right), 5(6)$-carboxybenzimidazole $(5(6)-\mathrm{COOH}-\mathrm{BI})$ and 2-benzimidazolylacetonitrile (2- $\left.\mathrm{CH}_{2} \mathrm{CN}-\mathrm{BI}\right)$, to corrosion inhibition efficiency was studied by Popova et al. in mild steel in $1 \mathrm{M} \mathrm{HCl}$ solution using gravimetric and polarization techniques. Popova et al. shows the order of corrosion inhibition efficiency is 5(6)- $\mathrm{NO}_{2-}$ $\mathrm{BI}<\mathrm{BI}<2-\mathrm{CH}_{3}-\mathrm{BI}<5(6)-\mathrm{COOH}-\mathrm{BI}<2-\mathrm{CH}_{2} \mathrm{OH}-\mathrm{BI}<2-\mathrm{NH}_{2}-\mathrm{BI}<2-\mathrm{CH}_{2} \mathrm{CN}-\mathrm{BI}<2-\mathrm{SH}-$ BI [10].

In addition to experimental studies, many theoretical studies have also been carried out. Obot et al. used a density functional calculation at B3LYP/6-311G++(d,p) level of theory to predict the substituent effect on benzimidazole corrosion inhibition performance [11]. The most relevant electronic parameters for corrosion inhibition ability can be explained systematically by these theoretical studies. In addition, theoretical study is able to explain in detail the mechanism of inhibition of corrosion by inhibitors. Corrosion inhibition efficiency from theoretical calculations also shows positive correlation with experimental studies. Zhang et al combined experimental and theoretical studies to study 2(4-pyridyl)-benzimidazole, benzimidazole and pyridine corrosion inhibition against mild steel in $1.0 \mathrm{M} \mathrm{HCl}$. A combination of weight loss, electrochemical measurements, DFT and MD simulations shows that substituent groups increase molecular inhibition ability [12]. Singh studied the effect of substituent on the efficiency of corrosion inhibitors of benzimidazole derivatives for $\mathrm{J} 55$ steel in $3.5 \mathrm{wt} \% \mathrm{NaCl}$ solution by combining experimental studies, DFT method and molecular dynamics simulation. A good correlation between electronic parameters and the efficiency of corrosion inhibitors is successfully presented [13].

In this report, the substituent effect on the corrosion inhibition performance of benzimidazole derivatives was studied using the ab initio MP2 and DFT methods. The substituent effect study is important due to the addition of substituents changes the structure and density of electrons which will certainly affect the strength of the interaction 
of benzoimidazole and metal. Secondly, the difference in substituent polarity also affects the solubility of bezimidazole which certainly affects its corrosion inhibition performance. Thirdly, many benzimidazole derivatives have successfully synthesized but not all have been tested experimentally as corrosion inhibitors. Therefore, molecular modeling will certainly help experimental research. In this study, the electron donating and withdrawing effect is presented in the correlations between molecular electronic parameters and corrosion inhibition efficiency. The second order interaction energy from natural bond orbital NBO analysis are used to show the contribution of each atom from the substituent active sites to increase the corrosion inhibition efficiency. The back donation effect from metals to inhibitors is also presented showing details of the interaction between inhibitors and metal surfaces.

\section{Computational method}

The optimized geometry of benzimidazole and its derivatives was calculated using density functional theory (DFT) and ab initio MP2. All calculations of the geometry parameters and intrinsic properties of benzimidazole and its derivatives were carried out using Gaussian 09 software [14]. The 6-311G (d,p) basis function was chosen for geometry optimization and electronic properties calculation of inhibitors whereas the combination of LanL2DZ ECP and 6-311G(d,p) was applied for determining the interaction energies and the second order interaction energy. Corrosion predominantly occurs in aqueous medium so the solvent effect was added using a polarized continuum model (PCM). Optimization of geometry inhibitors was not carried out on aqueous systems because it has a small effect on structural parameters and electronic energy [15-19].

The value of corrosion inhibition efficiency $\left(I E_{\text {theor. }} \%\right)$ was theoretically determined according to the previously published equation $[6,29]$. Theoretically the calculation of ionization potential $(I)$ and electron affinity $(A)$ uses the Koopman theorem [21]. Koopman's theorem explains the relationship between ionization potential $(I)$, electron affinity $(A)$, electronegativity $(\chi), E_{\mathrm{HOMO}}$ and $E_{\mathrm{LUMO}}$ energy as the following formula:

$$
\begin{gathered}
I=-E_{\mathrm{HOMO}} \\
A=-E_{\mathrm{LUMO}} \\
\chi=\frac{I+A}{2}
\end{gathered}
$$

The Pearson method describes the technique of calculating fraction of electron transfer $(\Delta N)$ between inhibitor molecules and metal surfaces. According to Pearson, when systems with different electronegativity come into contact, electrons will flow from lowelectronegativity systems to systems with high electronegativity. This electron flow stops when the chemical potential of the two systems is the same. To calculate fraction of electron transfer, the value of the theoretical electronegativity of iron used is $7 \mathrm{eV}$ [21] and 
assumed $I=A$ then the global hardness of $\mathrm{Fe}=0$ [22]. The $\Delta N$ is calculated based on Equation (4).

$$
\Delta N=\frac{\chi_{\mathrm{Fe}}-\chi_{\mathrm{inb}}}{2\left(\eta_{\mathrm{Fe}}+\eta_{\mathrm{inb}}\right)}
$$

For the studied molecules, the interaction energy can be calculated as follows:

$$
\Delta E=E_{\mathrm{Fe}-\mathrm{BI}}-\left(E_{\mathrm{Fe}}+E_{\mathrm{BI}}\right)
$$

Here, $E_{\mathrm{Fe}-\mathrm{BI}}$ was the complex energy, $E_{\mathrm{Fe}}$ the energy of metal salts and $E_{\mathrm{BI}}$ the energy of benzimidazole and its derivatives [23].

The electron donation intensity from the active side of the atom inhibitor was studied further using Natural Population Analysis (NBO) in terms of the second order interaction energy (E2). E2 describes the intensity of each electron donor between the Lewis Donor $(i)$ and non-Lewis Acceptor NBO $(j)$. E2 associated with $i \rightarrow j$ delocalization can be estimated as follows [24]:

$$
E 2=q i \frac{F(i, j)}{\varepsilon_{i}-\varepsilon_{j}}
$$

Here, $q i$ is the donor orbital occupancy, $\varepsilon_{i}, \varepsilon_{j}$ are diagonal elements (orbital energies), and $F(i, j)$ are off-diagonal elements, respectively, associated with the NBO Fock matrix.

\section{Results and discussion}

Addition of substituents to the benzimidazole framework is depicted in Scheme 1. Electron donating groups $\left(\mathrm{CH}_{3}, \mathrm{NH}_{2}, \mathrm{C}_{2} \mathrm{H}_{2}, \mathrm{OH}, \mathrm{CH}_{2} \mathrm{OH}, \mathrm{OCH}_{3}\right)$ and withdrawing groups $(\mathrm{COOH}$, $\mathrm{COOCH}_{3}, \mathrm{NO}_{2}$ ) are added to the carbon position in the imidazole part. As a consequence of using the DFT and MP2 methods, it is necessary to determine the accuracy of the method to assess the target system. Accuracy of theoretical calculations was tested through comparison of theoretical geometry parameters with X-ray structures of imidazole compounds. Experimental studies of imidazole structures were obtained from previous publication [25]. The good suitability between the structural parameters of the theoretical calculation and the experimental data is shown in Table 1 . The relatively small difference in bond lengths and binding angles averaging $0.01 \AA$ and $1.5^{\circ}$ between theoretical and experimental studies indicated that DFT/6-311G(d,p) and MP2/6-311G(d,p) showed high accuracy for the studied systems.

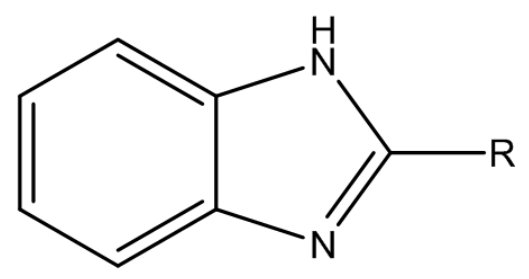

Scheme 1. $\mathrm{R}=\mathrm{CH}_{3}, \mathrm{NH}_{2}, \mathrm{C}_{2} \mathrm{H}_{2}, \mathrm{OH}, \mathrm{CH}_{2} \mathrm{OH}, \mathrm{OCH}_{3}, \mathrm{H}, \mathrm{COOH}, \mathrm{COOCH} \mathrm{H}_{3}$ and $\mathrm{NO}_{2}$. 
Table 1. Comparison of theoretical and experimental studies of imidazole geometrical parameters calculated using DFT/6-311G(d,p) and MP2/6-311G(d,p).

\begin{tabular}{cccccccc}
\hline Distance & DFT $(\AA)$ & MP2 $(\AA)$ & $\operatorname{Exp}(\AA)$ & Angle & DFT $(\AA)$ & MP2 & Exp \\
\hline N1-C2 & 1.3720 & 1.3710 & 1.347 & C2-N1-C5 & 107.7108 & 107.7664 & 107.40 \\
N1-C5 & 1.3823 & 1.3818 & 1.370 & N3-C2-N1 & 110.8038 & 110.8429 & 111.46 \\
N1-H1 & 1.0096 & 1.0096 & 0.870 & C2-N3-C4 & 105.8083 & 105.7353 & 105.02 \\
N3-C2 & 1.3190 & 1.3190 & 1.327 & C5-C4-N3 & 110.7803 & 110.8699 & 109.89 \\
N3-C4 & 1.3787 & 1.3776 & 1.384 & C4-C5-N1 & 104.8966 & 104.7853 & 106.22 \\
C4-C5 & 1.3703 & 1.3710 & 1.356 & N3-C2-C21 & 125.8661 & 126.1455 & 125.50 \\
C2-C21 & 1.4951 & 1.4969 & 1.487 & N1-C2-C21 & 123.3300 & 123.0115 & 123.03 \\
\hline
\end{tabular}

The electronic quantum parameters and corrosion inhibition efficiency of nonprotonated and protonated benzimidazole and its derivatives in aqueous medium have been studied (Table 2, Table 3, Table 4 and Table 5). Experimental studies of corrosion inhibition efficiency of benzimidazole compounds on mild steel showed an efficiency value of $73.10 \%$ measured using the gravimetric and EIS methods [9]. Theoretical corrosion inhibition efficiency was calculated based on the previously published equation [6]. Quantum parameters present the electronic properties of molecules so that they can be used to predict which compounds are more efficient as corrosion inhibitors. The substituent effect on electronic properties can be seen in Tabel 2, 3, 4 and 5. They showed that there are small differences in the value of electronic parameters between protonated and non-protonated species of benzilmidozole in aqueous medium. The corrosive inhibition performance trend remains the same in terms of the influence of the electron donating and withdrawing groups. The addition of electron donor groups has a better effect on the ability to inhibit corrosion than the addition of electron withdrawal groups. The addition of $\mathrm{NH}_{2}$ as electron donor group increases efficiency by $5 \%$, whereas the addition of $\mathrm{NO}_{2}$ decreases inhibition efficiency by $5 \%$. The influence of substituents $\left(\mathrm{CH}_{3}\right.$ and $\left.\mathrm{NH}_{2}\right)$ on the performance inhibition of benzilmidazole and its derivatives in aqueous medium was studied using gravimetric and electrochemical techniques have been reported by Popova et al. [27]. The study shows that the trend of inhibition performance follows BI$\mathrm{NH}_{2}>\mathrm{BI}-\mathrm{CH}_{3}$.

The corrosion inhibition performance trend of benzilmidazole is related to the energy values of HOMO and LUMO on inhibitor molecules. The HOMO energy ( $\left.E_{\text {Hомо }}\right)$ shows the nature of the molecule to donate electrons, while LUMO energy $\left(E_{\mathrm{LUMO}}\right)$ shows the nature of the molecule to receive electrons [28]. The bigger the $E_{\mathrm{HOMO}}$, the stronger an organic inhibitor attach to the metal surfaces. Thus, those molecular inhibitors have high anti-corrosion efficiency. The value of $E_{\mathrm{HOMO}}$ for $\mathrm{NH}_{2}$ based on DFT/6-311G(d,p) is $-5.6341 \mathrm{eV}$ greater than $\mathrm{NO}_{2}-6.9389 \mathrm{eV}$. The presence of nitro substituents reduces the reactivity of the benzene ring thus causing a weak bond of benzene ring with metal [26]. 
The same trend is also found in the results of the MP2 method. Furthermore, this is confirmed by Figure 1 which shows a linear HOMO energy correlation and inhibition of efficiency in aqueous phase, $r^{2}=0.9889$. This linear correlation trend is similar to that in a previous theoretical report [27].

Table 2. The electronic parameters of non-protonated benzimidazole and its derivatives calculated using B3LYP/6-311G(d,p) level of theory in aqueous medium.

\begin{tabular}{cccccccc}
\hline Substituent & $\boldsymbol{E}_{\text {номо }} \mathbf{e V}$ & $\boldsymbol{E}_{\mathbf{L u m o}} \mathbf{e V}$ & $\boldsymbol{I} \mathbf{e V}$ & $\boldsymbol{A} \mathbf{~ e V}$ & $\boldsymbol{X} \mathbf{e V}$ & $\Delta \boldsymbol{N}$ & $\boldsymbol{I}_{\text {theor. }}$ \\
\hline $\mathrm{H}$ & -6.4809 & -0.7970 & 6.4809 & 0.797 & 3.6389 & 0.5913 & 73.8000 \\
$\mathrm{CH}_{3}$ & -6.3204 & -0.7388 & 6.3204 & 0.7388 & 3.5296 & 0.6217 & 75.6276 \\
$\mathrm{NH}_{2}$ & -5.6341 & -0.2880 & 5.6341 & 0.288 & 2.9610 & 0.7554 & 83.4427 \\
$\mathrm{C}_{2} \mathrm{H}_{2}$ & -6.1694 & -1.5478 & 6.1694 & 1.5478 & 3.8586 & 0.6797 & 77.3471 \\
$\mathrm{OH}$ & -6.159 & -0.4879 & 6.159 & 0.4879 & 3.3234 & 0.6482 & 77.4655 \\
$\mathrm{CH}_{2} \mathrm{OH}$ & -6.3182 & -0.7045 & 6.3182 & 0.7045 & 3.5113 & 0.6214 & 75.6527 \\
$\mathrm{OCH}$ & -6.1158 & -0.4874 & 6.1158 & 0.4874 & 3.3016 & 0.6570 & 77.9575 \\
$\mathrm{CHO}$ & -6.7267 & -2.4030 & 6.7267 & 2.4030 & 4.5648 & 0.5632 & 71.0010 \\
$\mathrm{COOH}$ & -6.7204 & -2.0351 & 6.7204 & 2.0351 & 4.3777 & 0.5596 & 70.4391 \\
$\mathrm{COOCH}_{3}$ & -6.6913 & -1.9587 & 6.6913 & 1.9587 & 4.3250 & 0.5652 & 70.7705 \\
$\mathrm{NO}_{2}$ & -6.9389 & -3.1856 & 6.9389 & 3.1856 & 5.0622 & 0.5162 & 67.6562 \\
\hline
\end{tabular}

Table 3. The electronic parameters of protonated benzimidazole and its derivatives calculated using B3LYP/6-311G(d,p) level of theory in aqueous medium.

\begin{tabular}{lccccccc}
\hline \multicolumn{1}{c}{ Substituent } & $\boldsymbol{E}_{\text {номо }} \mathbf{e V}$ & $\boldsymbol{E}_{\mathbf{L U M O}} \mathbf{e V}$ & $\boldsymbol{I} \mathbf{~ e V}$ & $\boldsymbol{A} \mathbf{~ e V}$ & $\boldsymbol{X} \mathbf{e V}$ & $\Delta \boldsymbol{N}$ & $\boldsymbol{I}_{\text {theor. }}$ \\
\hline $\mathrm{H}$ & -7.4338 & -1.9897 & 7.4338 & 1.9896 & 4.7117 & 0.4203 & 73.8000 \\
$\mathrm{CH}_{3}$ & -7.3062 & -1.8732 & 7.3062 & 1.8732 & 4.5897 & 0.4436 & 75.0669 \\
$\mathrm{NH}_{2}$ & -6.7609 & -1.1265 & 6.7609 & 1.1265 & 3.9437 & 0.5424 & 80.4806 \\
$\mathrm{C}_{2} \mathrm{H}_{2}$ & -7.1541 & -2.6732 & 7.1541 & 2.6732 & 4.9136 & 0.4655 & 76.5770 \\
$\mathrm{OH}$ & -7.2140 & -1.4432 & 7.2140 & 1.4432 & 4.3286 & 0.4629 & 75.9827 \\
$\mathrm{CH}_{2} \mathrm{OH}$ & -7.335 & -1.8193 & 7.3351 & 1.8193 & 4.5772 & 0.4392 & 74.7806 \\
$\mathrm{OCH}_{3}$ & -7.1438 & -1.4375 & 7.1438 & 1.4375 & 4.2906 & 0.4747 & 76.6797 \\
$\mathrm{CHO}$ & -7.6703 & -3.6177 & 7.6703 & 3.6177 & 5.6440 & 0.3345 & 71.4524 \\
$\mathrm{COOH}$ & -7.9533 & 3.4278 & 7.9533 & -3.4278 & 2.2627 & 0.4162 & 68.6430 \\
$\mathrm{COOCH}_{3}$ & -7.6183 & -3.2416 & 7.6183 & -3.2416 & 5.4300 & 0.3587 & 71.9684 \\
$\mathrm{NO}_{2}$ & -7.8518 & -4.3010 & 7.8518 & 4.3010 & 6.0764 & 0.2600 & 69.6506 \\
\hline
\end{tabular}


Table 4. The electronic parameters of non-protonated benzimidazole and its derivatives calculated using MP2/6-311G (d,p) level of theory in aqueous medium.

\begin{tabular}{cccccccc}
\hline Substituent & $\boldsymbol{E}_{\mathbf{H O M O}} \mathbf{e V}$ & $\boldsymbol{E}_{\mathbf{L u M O}} \mathbf{e V}$ & $\boldsymbol{I} \mathbf{e V}$ & $\boldsymbol{A} \mathbf{e V}$ & $\boldsymbol{X} \mathbf{e V}$ & $\Delta \boldsymbol{N}$ & $\boldsymbol{I E}_{\text {theor. }}$ \\
\hline $\mathrm{H}$ & -8.4508 & 2.9952 & $\begin{array}{c}8.4508 \\
(8.47)^{*}\end{array}$ & -2.9952 & 2.7278 & 0.3732 & 73.8100 \\
$\mathrm{CH}_{3}$ & -8.2698 & 3.0501 & $\begin{array}{c}8.2698 \\
(8.24)^{*}\end{array}$ & -3.0501 & 2.6098 & 0.3878 & 75.3806 \\
& & & & & & & \\
$\mathrm{NH}_{2}$ & -7.7754 & 3.4855 & $(7.91)^{*}$ & -3.4855 & 2.1449 & 0.4311 & 79.6982 \\
$\mathrm{C}_{2} \mathrm{H}_{2}$ & -8.0083 & 2.1801 & 8.0083 & -2.1801 & 2.9141 & 0.4010 & 77.6643 \\
$\mathrm{OH}$ & -8.251 & 3.3138 & 8.251 & -3.3138 & 2.4686 & 0.3918 & 75.5448 \\
$\mathrm{CH}_{2} \mathrm{OH}$ & -8.2984 & 3.0811 & 8.2984 & -3.0811 & 2.6086 & 0.3859 & 75.1308 \\
$\mathrm{OCH}_{3}$ & -8.2059 & 3.3103 & 8.2059 & -3.3103 & 2.4478 & 0.3952 & 75.9386 \\
$\mathrm{CHO}$ & -8.3172 & 1.3845 & 8.3172 & -1.3845 & 3.4663 & 0.3642 & 74.9667 \\
$\mathrm{COOH}$ & -8.7204 & 8.7204 & 8.7204 & -8.7204 & 3.3778 & 0.3401 & 70.7583 \\
$\mathrm{COOCH}_{3}$ & -8.6831 & 1.7138 & 8.6831 & -1.7138 & 3.4846 & 0.3381 & 71.5885 \\
$\mathrm{NO}_{2}$ & -9.0034 & 0.4596 & 9.0034 & -0.4596 & 4.2719 & 0.2882 & 68.6559 \\
\hline
\end{tabular}

*experimental data [29]

Table 5. The electronic parameters of protonated benzimidazole and its derivatives calculated using MP2/6-311G (d,p) level of theory in aqueous medium.

\begin{tabular}{cccccccc}
\hline Substituent & $\boldsymbol{E}_{\text {номо }} \mathbf{e V}$ & $\boldsymbol{E}_{\mathbf{L u M o}} \mathbf{e V}$ & $\boldsymbol{I} \mathbf{e V}$ & $\boldsymbol{A} \mathbf{e V}$ & $\boldsymbol{X} \mathbf{e V}$ & $\Delta \boldsymbol{N}$ & $\boldsymbol{I} \boldsymbol{E}_{\text {theor. }}$ \\
\hline $\mathrm{H}$ & -9.4080 & 2.0258 & 9.4080 & -2.0258 & 3.6910 & 0.2893 & 73.8100 \\
$\mathrm{CH}_{3}$ & -9.2548 & 2.1306 & 9.2548 & -2.1306 & 3.5621 & 0.3019 & 75.0119 \\
$\mathrm{NH}_{2}$ & -8.8940 & 2.7967 & 8.8940 & -2.7967 & 3.0486 & 0.3379 & 77.8427 \\
$\mathrm{C}_{2} \mathrm{H}_{2}$ & -9.0080 & 1.1426 & 9.0080 & -1.1426 & 3.9327 & 0.3021 & 76.9482 \\
$\mathrm{OH}$ & -9.2924 & 2.5546 & 9.2924 & -2.5546 & 3.3689 & 0.3064 & 74.7173 \\
$\mathrm{CH}_{2} \mathrm{OH}$ & -9.3033 & 2.1684 & 9.3033 & -2.1684 & 3.5674 & 0.2992 & 74.6319 \\
$\mathrm{OCH}_{3}$ & -9.2355 & 2.5478 & 9.2355 & -2.5478 & 3.3438 & 0.3102 & 75.1634 \\
$\mathrm{CHO}$ & -9.5680 & 0.1662 & 9.5680 & -0.1662 & 4.7009 & 0.2361 & 72.5547 \\
$\mathrm{COOH}$ & -9.5682 & 0.37334 & 9.5682 & -0.3733 & 4.5974 & 0.2416 & 72.5531 \\
$\mathrm{COOCH}_{3}$ & -9.6004 & 0.4272 & 9.6004 & -0.4272 & 4.5866 & 0.2406 & 72.3006 \\
$\mathrm{NO}_{2}$ & -9.8687 & -0.7518 & 9.8687 & 0.7518 & 5.3103 & 0.1853 & 70.1957 \\
\hline
\end{tabular}


The ionization potential $(I)$ can be used to measure the reactivity of atoms or molecules. High ionization potential values indicate molecules have high reactivity while low ionization potential values indicate molecules have low reactivity [26, 27]. Tables 2 and 3 also show an increase in ionization potential which follows the increasing trend of

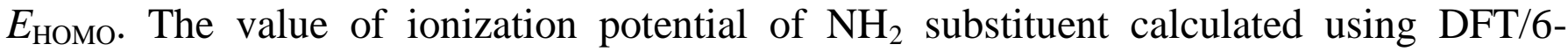
$311 \mathrm{G}(\mathrm{d}, \mathrm{p})$ is $5.6341 \mathrm{eV}$ which is lower than the ionization potential value for $\mathrm{NO}_{2}$, $-6.9389 \mathrm{eV}$. This is again predicted that $\mathrm{NH}_{2}$ will have a higher anti-corrosion efficiency than $\mathrm{NO}_{2}$ substituted benzimidazole. This trend is also found for the results of MP2 calculations. However, the ionization potential value must agree with the experimental results. Experimental ionization potential of benzimidazole is $8.47 \mathrm{eV}$ [30]. This means benzimidazole and its derivatives will have HOMO energy in the range of $+8 \mathrm{eV}$. The results of the DFT method show that the ionization potential value of $2.0 \mathrm{eV}$ lower than the experimental data. Based on these findings, the application of the DFT method in measuring corrosion inhibition performance needs to be reviewed because DFT fails to replicate experiments, especially important electronic parameters such as ionization potential. Therefore, the MP2 calculation gives much better results especially in the accuracy of the calculation of ionization potential.

Small values of electronegativity cause molecules to easily reach electronic equilibrium so that molecules become more reactive. The high value of electronegativity shows the opposite [28]. Table 1 shows the order of increase in the value of $\mathrm{NH}_{2}<\mathrm{OCH}_{3}<$ $\mathrm{OH}<\mathrm{C}_{2} \mathrm{H}_{2}<\mathrm{CH}_{2} \mathrm{OH}<\mathrm{CH}_{3}<\mathrm{CHO}<\mathrm{H}<\mathrm{COOCH}_{3}<\mathrm{COOH}<\mathrm{NO}_{2}$. The electronegativity value of $\mathrm{NH}_{2}$ substituted benzimidazole is $2.1449 \mathrm{eV}$, lower than the electronegativity value of $\mathrm{NO}_{2}, 4.2719 \mathrm{eV}$. Based on this electronegativity data, it can be predicted that $\mathrm{NH}_{2}$-substituted benzimidazole has a higher anti-corrosion efficiency than nitro substituents.

According to Lukovits [20] electron transfer will occur from the inhibitor to the surface of the metal and vice versa if $\Delta N$ is positive and the value is less than 3.6. Table 1 and 3 presents the value of the number of electrons transferred $(\Delta N)$. The presence of donor electron substituents increases the efficiency of corrosion inhibition because the number of electron transfers to the metal surface increases. The value of $\Delta N$ indicates that $\mathrm{NH}_{2}$ substituent is the best corrosion inhibitor because it has the highest electron transfer capability, whereas $\mathrm{NO}_{2}$ shows the lowest electron transfer capability. Thus, the $\mathrm{NO}_{2}$ substituent has the least inhibition efficiency. Figure 1 shows the positive correlation between the electrons transferred and corrosion inhibition efficacy in aqueous phase. The positive correlation between electrons transferred and corrosion inhibition efficiencies has a linearity of $r^{2}=0.9705$. This value of $\Delta N$ is directly proportional to HOMO energy, ionization potential and electronegativity. 

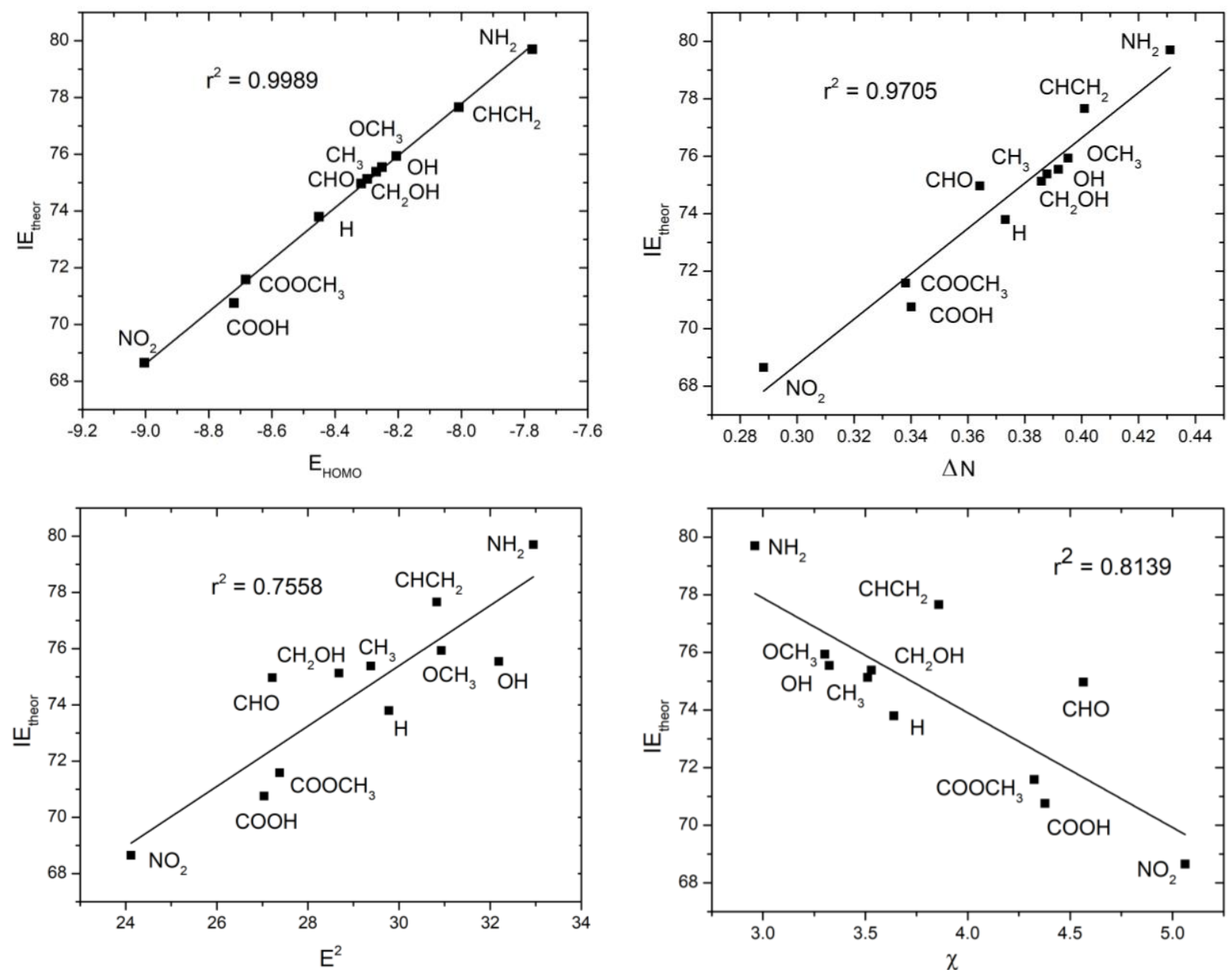

Figure 1. Correlation between corrosion inhibition efficiency $\left(I E_{\text {theor. }}\right)$ and molecular electronic parameters such as $E_{\mathrm{HOMO}}$, fraction of electron transfer, electronegativity and second order interaction energy.

In order to further study the interactions between inhibitors and metal, a geometry optimization was carried out for monocluster Fe and benzilimidazole and its derivatives. The level of molecular adsorption that occurs on the surface of $\mathrm{Fe}$ is represented by measuring the interaction energy between Fe and benzilmidazole. The interaction energy is related to the strength of the adsorption of molecules on the metal surface. The interaction energy between ferrous metal $(\mathrm{Fe})$ and benzilmidazole is calculated as the energy difference between the complex and its monomer [23]. The interaction mode between Fe and benzilimidazole involves the interaction between nitrogen and carbon benzilmidazole with Fe. The easy protonated benzilmidazole and its derivatives to undergo electron delocalized make them are able to transfer more electrons to the vacant Fe orbitals. Thus, the interaction energies of protonated benzilmidazole with Fe were slightly stronger compared to neutral benzimidazole molecules (Table 6). 
Table 6. Calculated dipole moment (Debye) and interaction energies $\Delta E\left(\mathrm{kcal} \cdot \mathrm{mol}^{-1}\right)$ of benzimidazole and its derivatives calculated by DFT/B3LYP combined LANL2DZ and 6-311G(d,p) level of theory.

\begin{tabular}{ccccc}
\hline \multirow{2}{*}{ Substituent } & \multicolumn{2}{c}{ Dipole Moment (Debye) } & \multicolumn{2}{c}{$\Delta \boldsymbol{E}\left(\mathbf{k c a l} \cdot \mathbf{m o l}^{-\mathbf{1}}\right.$ ) } \\
\cline { 2 - 5 } & Non-protonated & Protonated & Non-protonated & Protonated \\
\hline $\mathrm{H}$ & 4.7284 & 6.9000 & -23.9392 & -25.8600 \\
$\mathrm{CH}_{3}$ & 4.9454 & 6.1907 & -24.6030 & -25.2283 \\
$\mathrm{NH}_{2}$ & 6.3884 & 8.7368 & -23.1831 & -23.4735 \\
$\mathrm{C}_{2} \mathrm{H}_{2}$ & 4.6200 & 4.7247 & -23.2096 & -24.8827 \\
$\mathrm{OH}$ & 3.2045 & 6.1197 & -22.8138 & -23.6552 \\
$\mathrm{CH}_{2} \mathrm{OH}$ & 4.6231 & 6.1075 & -24.0956 & -24.7780 \\
$\mathrm{OCH}$ & 3.3896 & 5.1170 & -24.4886 & -23.1985 \\
$\mathrm{CHO}$ & 7.3633 & 2.3363 & -23.8017 & -22.5196 \\
$\mathrm{COOH}_{3}$ & 6.1858 & 2.0063 & -23.7472 & -23.9356 \\
$\mathrm{COOCH}_{3}$ & 6.5769 & 1.7258 & -23.7519 & -23.8630 \\
$\mathrm{NO}_{2}$ & 6.9190 & 4.3523 & -24.1753 & -24.0253 \\
\hline
\end{tabular}

Table 6 shows the moment dipole of neutral and protonated benzilmidazole and its derivatives. The greater the dipole moment, the stronger intra-molecular interactions that lead to the formation of strong adsorbed layers on the surface of metal. The dipole moment can be used to predict the total surface coverage of benzilmidazole and its derivatives on Fe surface. Molecules with a high dipole moment will exhibit large surface coverage when the molecules are absorbed on the metal surface [30]. This results in increased efficiency of corrosion inhibition of these molecules. The sequence of rising dipole moments from protonated benzilmidazole follows the trend of increasing the corrosion inhibition efficiency of these compounds.
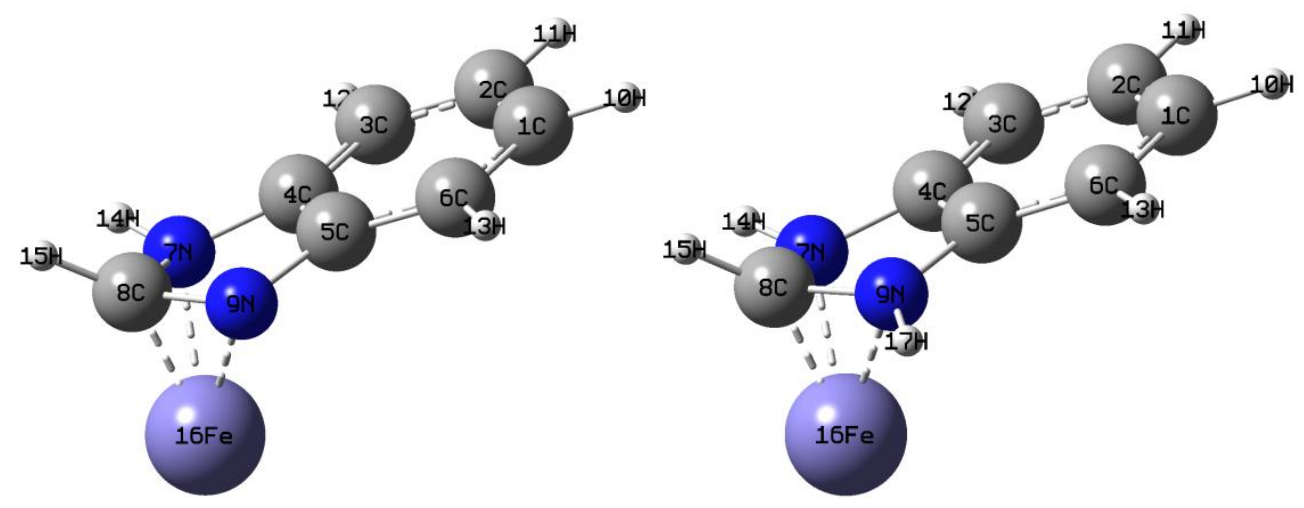

Figure 2. Schematic interaction of donor and back donation electron receptor between nonprotonated and protonated inhibitors and metal. 
Table 7. Selected second order interaction energy E2 $\left(\mathrm{kcal} \cdot \mathrm{mol}^{-1}\right)$ of non-protonated benzimidazole and its derivatives.

\begin{tabular}{|c|c|c|c|c|}
\hline \multirow{2}{*}{ Substituents } & $\begin{array}{c}\text { Maximum Donation } \\
\text { NBO }\end{array}$ & \multirow{2}{*}{$\begin{array}{l}\mathrm{E2} \\
\mathrm{kcal} \cdot \mathrm{mol}^{-1}\end{array}$} & \multirow{2}{*}{$\begin{array}{c}\text { Back Donation NBO } \\
\text { Donor }(i) \rightarrow \operatorname{Acceptor}(j)\end{array}$} & \multirow{2}{*}{$\begin{array}{c}\mathrm{E} 2 \\
\mathrm{kcal} \cdot \mathrm{mol}^{-1}\end{array}$} \\
\hline & Donor $(i) \rightarrow$ Acceptor $(j)$ & & & \\
\hline \multirow[t]{2}{*}{$\mathrm{H}$} & $\mathrm{LP}(1) \mathrm{N} 7 \rightarrow \mathrm{LP} *(4) \mathrm{Fe} 16$ & 29.78 & $\mathrm{LP}^{*}(3) \mathrm{Fe} 16 \rightarrow \mathrm{RY} \mathrm{F}^{*}(1) \mathrm{N} 7$ & 0.80 \\
\hline & $\mathrm{LP}(1) \mathrm{N} 9 \rightarrow \mathrm{LP}^{*}(5) \mathrm{Fe} 16$ & 6.26 & $\mathrm{LP}^{*}(2) \mathrm{Fe} 16 \rightarrow \mathrm{RY} *(2) \mathrm{N} 9$ & 0.77 \\
\hline \multirow[t]{2}{*}{$\mathrm{C}_{2} \mathrm{H}_{3}$} & $\mathrm{LP}(1) \mathrm{N} 7 \rightarrow \mathrm{LP} *(4) \mathrm{Fe} 20$ & 30.83 & $\mathrm{LP}^{*}(3) \mathrm{Fe} 20 \rightarrow \mathrm{RY} *(1) \mathrm{N} 7$ & 0.50 \\
\hline & $\mathrm{LP}(1) \mathrm{N} 9 \rightarrow \mathrm{LP}^{*}(5) \mathrm{Fe} 20$ & 6.26 & $\mathrm{LP}^{*}(3) \mathrm{Fe} 20 \rightarrow \mathrm{RY} *(2) \mathrm{N} 9$ & 0.72 \\
\hline \multirow[t]{2}{*}{$\mathrm{COOH}$} & $\mathrm{LP}(1) \mathrm{N} 7 \rightarrow \mathrm{LP}^{*}(4) \mathrm{Fe} 19$ & 27.04 & $\mathrm{LP}^{*}(3) \mathrm{Fe} 19 \rightarrow \mathrm{RY} *(1) \mathrm{N} 7$ & 0.63 \\
\hline & $\mathrm{LP}(1) \mathrm{N} 9 \rightarrow \mathrm{LP}^{*}(5) \mathrm{Fe} 19$ & 6.37 & $\mathrm{LP}^{*}(3) \mathrm{Fe} 19 \rightarrow \mathrm{RY} *(2) \mathrm{N} 9$ & 0.58 \\
\hline \multirow[t]{2}{*}{$\mathrm{OCH}_{3}$} & $\mathrm{LP}(1) \mathrm{N} 7 \rightarrow \mathrm{LP}^{*}(4) \mathrm{Fe} 20$ & 30.93 & $\mathrm{LP}^{*}(2) \mathrm{Fe} 20 \rightarrow \mathrm{BD}^{*}(1) \mathrm{N} 7-\mathrm{H} 16$ & 0.55 \\
\hline & $\mathrm{LP}(2) \mathrm{Fe} 20 \rightarrow \mathrm{RY}^{*}(2) \mathrm{N} 9$ & 0.50 & $\mathrm{LP}^{*}(2) \mathrm{Fe} 19 \rightarrow \mathrm{RY} *(1) \mathrm{N} 9$ & 0.52 \\
\hline \multirow[t]{2}{*}{$\mathrm{COOCH}_{3}$} & $\mathrm{LP}(1) \mathrm{N} 7 \rightarrow \mathrm{LP}^{*}(4) \mathrm{Fe} 22$ & 27.38 & $\mathrm{LP}^{*}(3) \mathrm{Fe} 22 \rightarrow \mathrm{RY} *(1) \mathrm{N} 7$ & 0.62 \\
\hline & $\mathrm{LP}(1) \mathrm{N} 9 \rightarrow \mathrm{LP} *(5) \mathrm{Fe} 22$ & 6.37 & $\mathrm{LP}^{*}(3) \mathrm{Fe} 22 \rightarrow \mathrm{RY} *(2) \mathrm{N} 9$ & 0.60 \\
\hline \multirow[t]{2}{*}{$\mathrm{CH}_{3}$} & $\mathrm{LP}(1) \mathrm{N} 7 \rightarrow \mathrm{LP}^{*}(4) \mathrm{Fe} 19$ & 29.38 & $\mathrm{LP}^{*}(2) \mathrm{Fe} 19 \rightarrow \mathrm{BD}^{*}(1) \mathrm{N} 7-\mathrm{H} 15$ & 0.68 \\
\hline & $\mathrm{LP}(1) \mathrm{N} 9 \rightarrow \mathrm{LP}^{*}(5) \mathrm{Fe} 19$ & 6.36 & $\mathrm{LP}^{*}(3) \mathrm{Fe} 19 \rightarrow \mathrm{RY}^{*}(2) \mathrm{N} 9$ & 0.61 \\
\hline \multirow[t]{2}{*}{$\mathrm{NH}_{2}$} & $\mathrm{LP}(1) \mathrm{N} 7 \rightarrow \mathrm{LP}^{*}(4) \mathrm{Fe} 18$ & 32.95 & $\mathrm{LP}^{*}(3) \mathrm{Fe} 18 \rightarrow \mathrm{RY} *(1) \mathrm{N} 7$ & 0.62 \\
\hline & $\mathrm{LP}(1) \mathrm{N} 9 \rightarrow \mathrm{LP}^{*}(5) \mathrm{Fe} 18$ & 5.94 & $\mathrm{LP}^{*}(4) \mathrm{Fe} 18 \rightarrow \mathrm{RY} *(5) \mathrm{N} 9$ & 0.72 \\
\hline \multirow[t]{2}{*}{$\mathrm{OH}$} & $\mathrm{LP}(1) \mathrm{N} 7 \rightarrow \mathrm{LP} *(4) \mathrm{Fe} 17$ & 32.19 & Less than threshold & \\
\hline & $\mathrm{LP}(3) \mathrm{Fe} 17 \rightarrow \mathrm{RY}^{*}(1) \mathrm{N} 7$ & 0.70 & Less than threshold & \\
\hline \multirow[t]{2}{*}{$\mathrm{NO}_{2}$} & $\mathrm{LP}(1) \mathrm{N} 5 \rightarrow \mathrm{LP} *(4) \mathrm{Fe} 18$ & 24.12 & $\mathrm{LP}^{*}(3) \mathrm{Fe} 18 \rightarrow \mathrm{RY} *(1) \mathrm{N} 5$ & 0.59 \\
\hline & $\mathrm{LP}(1) \mathrm{N} 2 \rightarrow \mathrm{LP} *(5) \mathrm{Fe} 18$ & 5.62 & $\mathrm{LP}^{*}(4) \mathrm{Fe} 18 \rightarrow \mathrm{RY} *(5) \mathrm{N} 2$ & 0.65 \\
\hline \multirow[t]{2}{*}{$\mathrm{CH}_{2} \mathrm{OH}$} & $\mathrm{LP}(1) \mathrm{N} 7 \rightarrow \mathrm{LP} *(4) \mathrm{Fe} 20$ & 28.68 & Less than threshold & \\
\hline & $\mathrm{LP}(2) \mathrm{Fe} 20 \rightarrow \mathrm{RY}^{*}(2) \mathrm{N} 9$ & 0.60 & Less than threshold & \\
\hline
\end{tabular}

The effect of substituent in terms of the intensity of the donor electron is studied further using the second-order interaction energy (E2) trend based on the natural bond orbitals (NBO) analysis [24]. The E2 energies of the non-protonated and protonated benzilmidazole and its derivatives obtained from the NBO analysis are depicted in Tables 7 and 8. The E2 shows the contribution of each inhibitor atoms in interacting with the metal surface. For benzilmidazole, the contribution of carbon is smaller than the nitrogen, so the discussion will focus on the ability of nitrogen to donate electrons (Figure 2). The NBO analysis shows differences in the ability of electron donors between non-protonated and protonated nitrogen in inhibitors. The E2 trend for non-protonated benzilmidazole and its 
derivatives shows the strong influence of nitrogen heteroatom N7 on the inhibitory performance. In contrast, nitrogen N9 indicates weak electron donor ability. It shows that the protonated nitrogen is preferred under aqueous conditions.

Table 8. Selected second order interaction energy E2 $\left(\mathrm{kcal} \cdot \mathrm{mol}^{-1}\right)$ of protonated benzimidazole and its derivatives

\begin{tabular}{|c|c|c|c|c|}
\hline \multirow{2}{*}{ Substituents } & Donation NBO & \multirow{2}{*}{$\begin{array}{l}\mathrm{E} 2 \\
\mathrm{kcal} \cdot \mathrm{mol}^{-1}\end{array}$} & \multirow{2}{*}{$\begin{array}{c}\text { Back Donation NBO } \\
\text { Donor }(i) \rightarrow \text { Acceptor }(j)\end{array}$} & \multirow{2}{*}{$\begin{array}{c}\mathrm{E} 2 \\
\mathrm{kcal} \cdot \mathrm{mol}^{-1}\end{array}$} \\
\hline & Donor $(i) \rightarrow$ Acceptor $(j)$ & & & \\
\hline \multirow[t]{2}{*}{$\mathrm{H}$} & $\mathrm{LP}(1) \mathrm{N} 7 \rightarrow \mathrm{LP} *(4) \mathrm{Fe} 16$ & 18.02 & $\mathrm{LP}^{*}(3) \mathrm{Fe} 17 \rightarrow \mathrm{RY} \mathrm{H}^{*}(1) \mathrm{N} 7$ & 0.51 \\
\hline & $\mathrm{LP} 1) \mathrm{N} 9 \rightarrow \mathrm{LP}^{*}(5) \mathrm{Fe} 16$ & 25.48 & $\mathrm{LP}^{*}(3) \mathrm{Fe} 17 \rightarrow \mathrm{RY} *(1) \mathrm{N} 9$ & 0.60 \\
\hline \multirow[t]{2}{*}{$\mathrm{C}_{2} \mathrm{H}_{2}$} & $\mathrm{LP}(1) \mathrm{N} 7 \rightarrow \mathrm{LP}^{*}(4) \mathrm{Fe} 20$ & 22.20 & $\mathrm{LP}^{*}(3) \mathrm{Fe} 20 \rightarrow \mathrm{RY} \mathrm{H}^{*}(1) \mathrm{N} 7$ & 0.51 \\
\hline & $\mathrm{LP}(1) \mathrm{N} 9 \rightarrow \mathrm{LP} *(5) \mathrm{Fe} 20$ & 24.85 & $\mathrm{LP}^{*}(3) \mathrm{Fe} 20 \rightarrow \mathrm{RY} *(2) \mathrm{N} 9$ & 0.55 \\
\hline \multirow[t]{2}{*}{$\mathrm{COOH}$} & $\mathrm{LP}(1) \mathrm{N} 7 \rightarrow \mathrm{LP} *(4) \mathrm{Fe} 19$ & 20.12 & $\mathrm{LP}^{*}(3) \mathrm{Fe} 19 \rightarrow \mathrm{RY} \mathrm{H}^{*}(1) \mathrm{N} 7$ & 0.52 \\
\hline & $\mathrm{LP}(1) \mathrm{N} 9 \rightarrow \mathrm{LP} *(5) \mathrm{Fe} 19$ & 26.54 & $\mathrm{LP}^{*}(2) \mathrm{Fe} 19 \rightarrow \mathrm{RY} \mathrm{H}^{*}(1) \mathrm{N} 9$ & 0.60 \\
\hline \multirow[t]{2}{*}{$\mathrm{CH}_{3}$} & $\mathrm{LP}(1) \mathrm{N} 7 \rightarrow \mathrm{LP}^{*}(4) \mathrm{Fe} 19$ & 20.35 & $\mathrm{LP}^{*}(3) \mathrm{Fe} 19 \rightarrow \mathrm{RY} \mathrm{Y}^{*}(1) \mathrm{N} 7$ & 0.52 \\
\hline & $\mathrm{LP}(1) \mathrm{N} 9 \rightarrow \mathrm{LP} *(5) \mathrm{Fe} 19$ & 24.91 & $\mathrm{LP}^{*}(2) \mathrm{Fe} 19 \rightarrow \mathrm{RY} \mathrm{H}^{*}(1) \mathrm{N} 9$ & 0.61 \\
\hline \multirow[t]{2}{*}{$\mathrm{COOCH}_{3}$} & $\mathrm{LP}(1) \mathrm{N} 7 \rightarrow \mathrm{LP}^{*}(4) \mathrm{Fe} 22$ & 20.19 & $\mathrm{LP}^{*}(3) \mathrm{Fe} 22 \rightarrow \mathrm{RY} *(1) \mathrm{N} 7$ & 0.52 \\
\hline & $\mathrm{LP}(1) \mathrm{N} 9 \rightarrow \mathrm{LP} *(5) \mathrm{Fe} 22$ & 26.28 & $\mathrm{LP}^{*}(2) \mathrm{Fe} 22 \rightarrow \mathrm{RY} *(1) \mathrm{N} 9$ & 0.62 \\
\hline \multirow[t]{2}{*}{$\mathrm{OCH}_{3}$} & $\mathrm{LP}(1) \mathrm{N} 7 \rightarrow \mathrm{LP} *(4) \mathrm{Fe} 20$ & 18.52 & $\mathrm{LP}^{*}(3) \mathrm{Fe} 20 \rightarrow \mathrm{RY}^{*}(1) \mathrm{N} 7$ & 0.52 \\
\hline & $\mathrm{LP}(1) \mathrm{N} 9 \rightarrow \mathrm{LP} *(5) \mathrm{Fe} 20$ & 26.00 & $\mathrm{LP}^{*}(2) \mathrm{Fe} 20 \rightarrow \mathrm{RY} *(1) \mathrm{N} 9$ & 0.62 \\
\hline \multirow[t]{2}{*}{$\mathrm{NH}_{2}$} & $\mathrm{LP}(1) \mathrm{N} 7 \rightarrow \mathrm{LP}^{*}(4) \mathrm{Fe} 22$ & 20.54 & $\mathrm{LP}^{*}(3) \mathrm{Fe} 18 \rightarrow \mathrm{RY} *(1) \mathrm{N} 7$ & 0.69 \\
\hline & $\mathrm{LP}(1) \mathrm{N} 9 \rightarrow \mathrm{LP}^{*}(5) \mathrm{Fe} 22$ & 26.82 & $\mathrm{LP}^{*}(2) \mathrm{Fe} 18 \rightarrow \mathrm{RY}{ }^{*}(1) \mathrm{N} 9$ & 0.50 \\
\hline \multirow[t]{2}{*}{$\mathrm{OH}$} & $\mathrm{LP}(1) \mathrm{N} 7 \rightarrow \mathrm{LP}^{*}(5) \mathrm{Fe} 17$ & 20.18 & Less than threshold & \\
\hline & $\mathrm{LP}(2) \mathrm{N} 9 \rightarrow \mathrm{LP}^{*}(4) \mathrm{Fe} 17$ & 24.18 & Less than threshold & \\
\hline \multirow[t]{2}{*}{$\mathrm{NO}_{2}$} & $\mathrm{LP}(1) \mathrm{N} 5 \rightarrow \mathrm{LP} *(4) \mathrm{Fe} 18$ & 17.39 & $\mathrm{LP}^{*}(2) \mathrm{Fe} 18 \rightarrow \mathrm{RY}^{*}(1) \mathrm{N} 2$ & 0.60 \\
\hline & $\mathrm{LP}(1) \mathrm{N} 2 \rightarrow \mathrm{LP}^{*}(5) \mathrm{Fe} 18$ & 27.23 & $\mathrm{LP}^{*}(3) \mathrm{Fe} 18 \rightarrow \mathrm{RY} *(1) \mathrm{N} 5$ & 0.51 \\
\hline \multirow[t]{2}{*}{$\mathrm{CH}_{2} \mathrm{OH}$} & $\mathrm{LP}(1) \mathrm{N} 7 \rightarrow \mathrm{LP} *(4) \mathrm{Fe} 20$ & 21.14 & Less than threshold & \\
\hline & LP (1)N9 $\rightarrow$ LP*(5)Fe20 & 23.13 & Less than threshold & \\
\hline
\end{tabular}

Further studies are directed at the protonated conditions of both nitrogen atoms from benzimidazole and their derivatives. An E2 analysis for protonated benzimidazole shows that both nitrogen atoms, N7 and N9, contribute almost equally in terms of donating electrons. Table 6 indicates that N9 has just slightly higher contribution than N7 in donating electrons to the iron surface. It can be explained by the optimal delocalization of electrons on the $\mathrm{N} 7=\mathrm{C} 8=\mathrm{N} 9$ side of benzimidazole which makes it easier for the two 
nitrogen atoms to donate their electrons to the metal surface [23]. In addition to donating electrons, nitrogen atoms also receive electron back donation from iron, even though their $\mathrm{E} 2$ value is small. Table 5 and 6 show that the $\mathrm{NH}_{2}$ substituent has the highest E2 values, the trend of $\mathrm{E} 2$ value can be used to explain why the addition of $\mathrm{NH}_{2}$ in benzimidazole increases the inhibitory ability of its corrosion. This trend of E2 shows a positive correlation $\left(r^{2}=0.813\right)$ with corrosion inhibition efficiency as shown in Figure 1. Thus, it can be concluded that the results of the second-order interaction energies value are in accordance with the electronic parameters.

\section{Conclusion}

Density functional theory DFT and Møller-Plesset perturbation theory MP2 was applied to examine the effect of electron-donating and withdrawing subtituents on the efficiency of corrosion inhibition of non-protonated and protonated benzilmidazole and its derivatives. The electron donating substituents $\mathrm{CH}_{3}, \mathrm{NH}_{2}, \mathrm{C}_{2} \mathrm{H}_{2}, \mathrm{OH}, \mathrm{CH}_{2} \mathrm{OH}, \mathrm{OCH}_{3}$, increase the corrosion inhibition efficiency of benzimidazole and electron withdrawing substituents, $\mathrm{COOH}, \mathrm{COOCH}_{3}, \mathrm{NO}_{2}$, giving the opposite effect. The prediction results of corrosion inhibition efficiency agree with the experiment. The HOMO energy indicates $\mathrm{NH}_{2}$ is able to donate electrons with the highest intensity compared to other substituents, while $\mathrm{NO}_{2}$ gives the least electron transfer to the metal surface. This trend is followed by other intrinsic properties such as LUMO energy, electronic affinity, electronegativity, fraction of electron transfer, ionization potential calculated using both the DFT and MP2 approaches, although DFT fails to follow the ionization potential of the experimental results. The positive correlation between corrosion inhibition efficiency and intrinsic properties is clearly seen. Furthermore, the second order interaction energy predicts the nitrogen active side of benzimidazole and its derivatives play significant role during adsorption processes at metal surfaces.

\section{Acknowledgments}

Financially supported from Penelitian Dasar RISTEKDIKTI Indonesia Grant Number: 1826/UN18.L1/PP/2019 is gratefully acknowledged.

\section{References}

1. M. El Faydy, M. Rbaa, L. Lakhrissi, B. Lakhrissi, I. Warad, A. Zarrouk and I.B. Obot, Corrosion protection of carbon steel by two newly synthesized benzimidazol-2-ones substituted 8-hydroxyquinoline derivatives in $1 \mathrm{M} \mathrm{HCl}$ : Experimental and theoretical study, Surf. Interfaces, 2019, 14, 222-237. doi: 10.1016/j.surfin.2019.01.005

2. W. Zhang, H.J. Li, M. Wang, L.J. Wang, A.H. Zhang and Y.C. Wu, Highly effective inhibition of mild steel corrosion in $\mathrm{HCl}$ solution by using pyrido [1,2-a] benzimidazoles, New J. Chem., 2019, 43, no. 1, 413-426. doi: 10.1039/C8NJ04028A 
3. I.B. Onyeachu, I.B. Obot, A.A. Sorour and M.I. Abdul-Rashid, Green corrosion inhibitor for oilfield application I: Electrochemical assessment of 2-(2-pyridyl) benzimidazole for API X60 steel under sweet environment in NACE brine ID196, Corros. Sci., 2019, 150, 183-193. doi: 10.1016/j.corsci.2019.02.010

4. G.A. Zhang, X. Hou, B.S. Hou and H.F. Liu, Benzimidazole derivatives as novel inhibitors for the corrosion of mild steel in acidic solution: Experimental and theoretical studies, J. Mol. Liq., 2019, 278, 413-427. doi: 10.1016/j.molliq.2019.01.060

5. G. Bereket, E. Hür and C. Öğretir, Quantum chemical studies on some imidazole derivatives as corrosion inhibitors for iron in acidic medium, J. Mol. Struct.: THEOCHEM, 2002, 578, no. 1-3, 79-88. doi: 10.1016/S0166-1280(01)00684-4

6. H.R. Obayes, G.H. Alwan, A.H. MJ Alobaidy, A.A. Al-Amiery, A.A.H. Kadhum and A.B. Mohamad, Quantum chemical assessment of benzimidazole derivatives as corrosion inhibitors, Chem. Cent. J., 2014, 8, no. 1, 21-28. doi: 10.1186/1752-153X-8$\underline{21}$

7. P.M. Niamien, F.K. Essy, A. Trokourey, A. Yapi, H.K. Aka and D. Diabate, Correlation between the molecular structure and the inhibiting effect of some benzimidazole derivatives, Mater. Chem. Phys., 2012, 136, no. 1, 59-65. doi: 10.1016/j.matchemphys.2012.06.025

8. K.F. Khaled, The inhibition of benzimidazole derivatives on corrosion of iron in $1 \mathrm{M}$ $\mathrm{HCl}$ solutions, Electrochim. Acta, 2003, 48, no. 17, 2493-2503. doi: 10.1016/S00134686(03)00291-3

9. J. Aljourani, K. Raeissi and M.A. Golozar, Benzimidazole and its derivatives as corrosion inhibitors for mild steel in 1M HCl solution, Corros. Sci., 2009, 51, no. 8, 1836-1843. doi: $10.1016 /$ j.corsci.2009.05.011

10. A. Popova, M. Christov, S. Raicheva and E. Sokolova, Adsorption and inhibitive properties of benzimidazole derivatives in acid mild steel corrosion, Corros. Sci., 2004, 46, no. 6, 1333-1350. doi: 10.1016/j.corsci.2003.09.025

11. I.B. Obot and N.O. Obi-Egbedi, Theoretical study of benzimidazole and its derivatives and their potential activity as corrosion inhibitors. Corros. Sci., 2010, 52, no. 2, 657660. doi: $10.1016 /$ j.corsci.2009.10.017

12. F. Zhang, Y. Tang, Z. Cao, W. Jing, Z. Wu and Y. Chen, Performance and theoretical study on corrosion inhibition of 2-(4-pyridyl)-benzimidazole for mild steel in hydrochloric acid, Corros. Sci., 2012, 61, 1-9. doi: 10.1016/j.corsci.2012.03.045

13. A. Singh, K. Ansari, M. Quraishi and H. Lgaz, Effect of electron donating functional groups on corrosion inhibition of J55 steel in a sweet corrosive environment: experimental, density functional theory, and molecular dynamic simulation, Materials, 2019, 12, no. 1, 17. doi: $10.3390 / \mathrm{ma12010017}$

14. M.J. Frisch, G.W. Trucks, H.B. Schlegel et al., Gaussian 09, Gaussian, Inc., Wallingford, CT, 2009. 
15. S. Hadisaputra, L.R. Canaval, H.D. Pranowo and R. Armunanto, Theoretical study of substituent effects on Cs+/Sr2+-dibenzo-18-crown-6 complexes, Monats. Chem., 2014, 145, no. 5, 737-745. doi: $10.1007 / \mathrm{s} 00706-013-1129-\mathrm{x}$

16. S. Hamdiani, I.H. Rohimah, N. Nuryono, A.A. Purwoko, L.R.T. Savalas and S. Hadisaputra, $a b$ initio Study of Corrosion Inhibition Performance of Dibenzo-diaza15-crown-5 and its Heterocyclic Analogs, Asian J. Chem., 2019, 31, no. 2, 303-308. doi: 10.14233 /ajchem.2019.21556

17. S. Hadisaputra, A.A. Purwoko, I. Ilhamsyah, S. Hamdiani, D. Suhendra, N. Nuryono and B. Bundjali, A combined experimental and theoretical study of (E)-ethyl 3-(4methoxyphenyl) acrylate as corrosion inhibitor of iron in $1 \mathrm{M} \mathrm{HCl}$ solutions, Int. J. Corros. Scale Inhib., 2018, 7, no. 4, 633-647. doi: 10.17675/2305-6894-2018-7-4-10

18. S. Hadisaputra, L.R. Canaval, H.D. Pranowo and R. Armunanto, Theoretical Study on the Extraction of Alkaline Earth Salts by 18-Crown-6: Roles of Counterions, Solvent Types and Extraction Temperatures, Indones. J. Chem., 2014, 14, no. 2, 199-208. doi: $\underline{10.22146 / i j c .21259}$

19. S. Hadisaputra, A.A. Purwoko, S. Hamdiani and N. Nuryono, Which anthocyanin is the best corrosion inhibitor?, In IOP Conference Series: Materials Science and Engineering, 2019, 509, no. 1, 012129. doi: 10.1088/1757-899X/509/1/012129

20. E. Lukovits, F. Kalman and F. Zucchi, Corrosion inhibitors - correlation between electronic structure and efficiency, Corrosion, 2001, 57, no. 1, 3-8. doi: $10.2174 / 1876503300902010083$

21. S. Martinez, Inhibitory mechanism of mimosa tannin using molecular modeling and substitutional adsorption isotherms, Mater. Chem. Phys., 2002, 77, no. 1, 97-102. doi: 10.1016/S0254-0584(01)00569-7

22. M.J.S. Dewar and W. Thiel, Ground states of molecules 59 MNDO study of SN2 reactions and related processes, J. Am. Chem. Soc., 1963, 85, 3531-3539. doi: $\underline{10.1021 / \mathrm{ja} 00324 \mathrm{a} 022}$

23. I. Abdulazeez, M. Khaled and A.A. Al-Saadi, Impact of electron-withdrawing and electron-donating substituents on the corrosion inhibitive properties of benzimidazole derivatives: A quantum chemical study, J. Mol. Struct., 2019, 1196, 348-355. doi: 10.1016/j.molstruc.2019.06.082

24. F. Weinhold, Natural bond orbital analysis: a critical overview of relationships to alternative bonding perspectives, J. Comp. Chem., 2012, 33, no. 30, 2363-2379. doi: $\underline{10.1002 / j \mathrm{jcc} .23060}$

25. R.K. McMullan, J. Epstein, J.R. Ruble and B.M. Craven, The crystal structure of imidazole at $103 \mathrm{~K}$ by neutron diffraction, Acta Cryst. B, 1976, 35, no. 3, 688-691. doi: $10.1107 / \mathrm{S} 0567740879004441$

26. P. Politzer, L. Abrahmsen and P. Sjoberg, Effects of amino and nitro substituents upon the electrostatic potential of an aromatic ring, J. Am. Chem. Soc., 1984, 106, no. 4, 855-860. doi: $10.1021 / \mathrm{ja} 00316 \mathrm{a} 005$ 
27. A. Popova, M. Christov and T. Deligeorigiev, Influence of the molecular structure on the inhibitor properties of benzimidazole derivatives on mild steel corrosion in $1 \mathrm{M}$ hydrochloric acid, Corrosion, 2003, 59, no. 9, 756-764. doi: $10.5006 / 1.3277604$

28. S. Hadisaputra, S. Hamdiani, M.A. Kurniawan and N. Nuryono, Influence of macrocyclic ring size on the corrosion inhibition efficiency of dibenzo crown ether: a density functional study, Indones. J. Chem., 2017, 17, no. 3, 431-438. doi: 10.22146/ijc.26667

29. V.K. Turchaninov, E.A. Motvienko, L.I. Larina and A.M. Shulunova, L.V. Baikalova and V.A. Lopyrev, The study of benzimidazoles, Russ. Chem. Bull., 1993, 42, no. 10, 1683-1689. doi: $10.1007 / \mathrm{BF} 00697040$

30. B.D. Mert, M. Erman Mert, G. Kardas and B. Yazıc1, Experimental and theoretical investigation of 3-amino-1,2,4-triazole-5-thiol as a corrosion inhibitor for carbon steel in $\mathrm{HCl}$ medium, Corros. Sci., 2011, 53, no. 12, 4265-4272. doi: $\underline{10.1016 / j . c o r s c i .2011 .08 .038 ~}$ 